\title{
Obituary
}

\section{Dr Karl Ludwig Lemberg}

Spinal Cord (2003) 41, 572. doi:10.1038/sj.sc.3101504

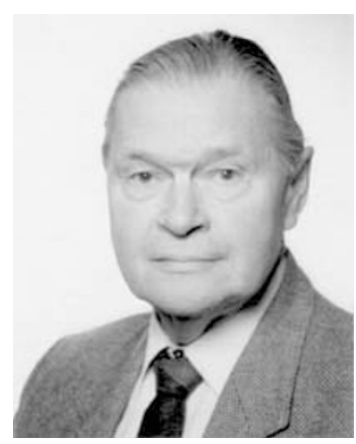

Dr Karl Ludwig Lemberg died on 28 August 2002. He was one of the great pioneers in the treatment of spinal cord injuries in the German Republic. Even as early as 1950, Dr Lemberg had founded a special unit specializing in the treatment of paralysis in Bayreuths Hohe Warte Hospital. In 1951, he spent several months working with Sir Ludwig Guttmann in Stoke Mande-

ville in England, and with the added knowledge that he had gained there he was in a position to extend the unit even further. In 1974, Dr Lemberg's tireless efforts were finally rewarded with the opening of a modern Spinal Cord Injury Clinic with 70 beds. Dr Lemberg's clinical experience and knowledge has been reported in many medical journals and accounted at lectures at numerous medical congresses. Dr Lemberg was one of the founders and an Honorary Member of the German Speaking Medical Society of Paraplegia-DMGP. From its onset, he was also a member of the International Medical Society of Paraplegia-IMSOP. Until his death at 83 years, Dr Lemberg was in close contact with his former patients and remained a fatherly consellor and friend.

Professor W Grüninger Bayreuth, Germany 